\title{
Coupled Motion and Sloshing Analysis of a Rigid Cylindrical - Closed Fish Cage in Regular Waves
}

Tan, Yuelin ; Shao, Yanlin; Read, Robert

Published in:

38th International Conference on Ocean, Offshore \& Arctic Engineering

Link to article, DOI:

10.1115/OMAE2019-96002

Publication date:

2019

Document Version

Peer reviewed version

Link back to DTU Orbit

Citation (APA):

Tan, Y., Shao, Y., \& Read, R. (2019). Coupled Motion and Sloshing Analysis of a Rigid Cylindrical - Closed Fish Cage in Regular Waves. In 38th International Conference on Ocean, Offshore \& Arctic Engineering (Vol. 6: Ocean Space Utilization). [OMAE2019-96002] American Society of Mechanical Engineers. https://doi.org/10.1115/OMAE2019-96002

\section{General rights}

Copyright and moral rights for the publications made accessible in the public portal are retained by the authors and/or other copyright owners and it is a condition of accessing publications that users recognise and abide by the legal requirements associated with these rights.

- Users may download and print one copy of any publication from the public portal for the purpose of private study or research.

- You may not further distribute the material or use it for any profit-making activity or commercial gain

- You may freely distribute the URL identifying the publication in the public portal 


\title{
COUPLED MOTION AND SLOSHING ANALYSIS OF A RIGID CYLINDRICAL CLOSED FISH CAGE IN REGULAR WAVES
}

\author{
Yuelin Tan ${ }^{1}$, Yanlin Shao, Robert Read \\ Technical University of Denmark \\ Lyngby Denmark
}

\section{ABSTRACT}

In this paper, a coupled numerical model in the time domain has been developed to study the interaction between interior liquid sloshing and the motion of a cylindrical closed fish cage when the cage is exposed to regular waves. The single-dominant nonlinear multimodal theory for sloshing in a cylindrical cage presented in [1] was implemented to simulate the liquid responses in the cage. A time-domain simulator based on the Cummins formulation of the equations of motion [2] is used to solve for the cage motion, while WAMIT is used to provide all required frequency-domain hydrodynamic coefficients for the external diffraction/radiation problems. Details of the coupling between cage motion and sloshing will be presented.

The coupled solver is verified against the linear frequencydomain solution from WAMIT for the very small wave steepness, where linear theory is valid. The results show that the sloshing effect is a vital factor in the coupling process, which means that the liquid in the closed cage cannot be treated as a solid mass. This is particularly true close to the resonant frequencies of the liquid in the tank. Furthermore, the importance of nonlinearity due to sloshing responses is investigated by applying incident waves with different steepness. When the cage is exposed to regular waves, if certain criteria are met, nonlinear swirling waves are observed in the closed cage. The nonlinear swirling waves are due to the interactions between different sloshing modes, which can only be explained by a proper nonlinear theory, such as the multimodal theory applied in this study. The influence of the swirling waves on the cage motions will also be discussed in the paper. How this effect will impact the design of a closed fish cage and its mooring system can only be answered by studying the cage responses in irregular waves, which is the subject of ongoing research.

\section{INTRODUCTION}

To meet the Sustainable Development Goals (SDGs) presented by the United Nations, the aquaculture industry has gained special attention for contributing to several of the SDGs, such as Zero Hunger (GOAL 2), Clean Water and Sanitation (GOAL 6) and Life below Water (GOAL 14). Closed fish cages have been proposed by the aquaculture industry to efficiently solve the problems of sea lice and fish escape, which have a strong influence on fish health and production levels.

${ }^{1}$ Contact author: brtan1314@gmail.com
Meanwhile, the pollution that is caused by the fish and feed can be filtered through the pipes around the cage. Therefore, the ocean environment will be protected effectively, which is essential if marine aquaculture is to be sustainable. An example of a cylindrical closed fish cage is shown in Fig. 1.

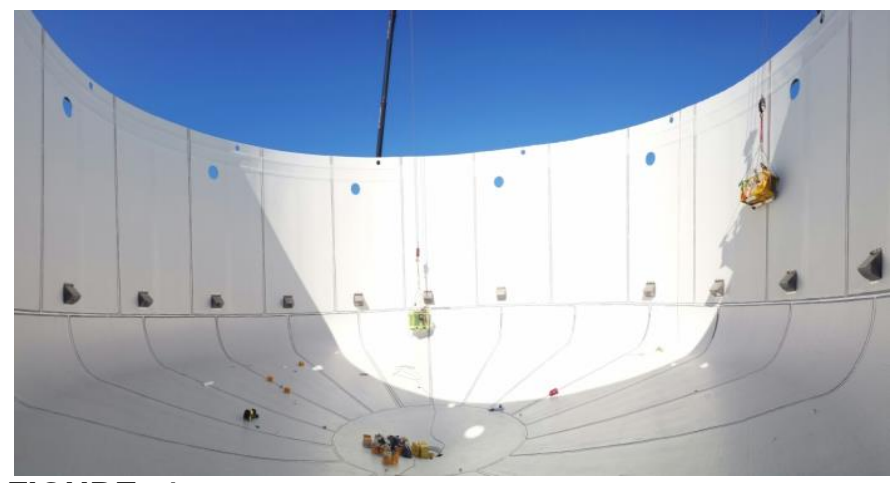

FIGURE 1: RIGID CYLINDRICAL CLOSED CAGE FROM AQUAFARM EQUIPMENT [3]

Despite their importance, there has been limited research investigating the behavior of closed cages when they are exposed to waves. In 2015, the closed fish cage "AquaDorm" from MSC and Norpartners damaged and sunk by storm Ole, which was reported to lead to EUR 1.4 million cost due to the damage. This accident encouraged designers and researchers to investigate the cage behaviors in the real waves. More knowledge of the closed fish cage is now expected to understand the behavior of the closed cages in waves, and to guide the design of closed fish cages in general.

This paper concerns the floating rigid cylindrical fish cage design, which has a non-negligible interior fluid with a free surface. The fundamental theories of the liquid sloshing problem inside tanks has been comprehensively reviewed in [1] and [4], where wave free surface elevation and hydrodynamic loads induced by liquid sloshing have been extensively studied. The sloshing problems have also been studied by many others, for example in [5], where a finite element method was used to analyze sloshing waves in a three-dimensional tank. Among others, coupled ship motions and sloshing analysis have been carried out for ships, using either Computational Fluid Dynamic (CFD) [6] or the multimodal approach [7] for sloshing. For the 
flexible floating cylindrical cage, the responses of the cage in waves have been studied by [8], followed by experimental studies on the wave induced responses [9], where the drag forces on a half ellipsoidal closed flexible fish cage were modeled. Kristiansen et al. [10] carried out model tests of a closed fish cage in regular waves, and compared with linear numerical results in the frequency domain. The results showed that the influence of sloshing on the rigid body motion is significant. Since a linear theory was used for the sloshing in the cage, the significance of the nonlinear sloshing effects was not clear. One example is the nonlinear swirling waves that may occur in the cylindrical tank for certain combinations of excitation frequency and amplitude. To the authors' knowledge, no previous numerical analysis on the motion of the cylindrical closed fish cage with consideration of different possible types of nonlinear waves e.g. swirling waves in the tank, have been reported in the literature.

In the present paper, a numerical model for simulating the rigid body motion of a cylindrical based cage will be presented. The interior wave sloshing effects and exterior wave hydrodynamic effects will be introduced separately. Thereafter, the coupling between sloshing in the cage and cage motion in waves will be presented. Verification of the coupled model will be shown before the final results from the coupled numerical model are presented. The nonlinear effects of sloshing will be examined by varying the wave steepness of the incident waves. The occurrence of swirling waves in a freely floating closed cylindrical rigid cage in regular waves is also confirmed through numerical analysis. Influence of swirling waves will be analyzed in details for cage motion and sloshing induced forces on the cage. Only results for regular waves are presented. However, the coupled model is ready for analysis using irregular waves.

\section{Multimodal solutions for sloshing in a cylindrical cage}

The fluid in the cage is assumed to be inviscid, incompressible and irrotational. Thus, the potential flow theory can be applied in this study. The velocity potential, which is a scalar function, represents the solution in the fluid. In specific, the linear and the single dominant nonlinear multimodal theories in [1] will be used. For completeness, the governing equation, boundary conditions and multimodal theories will only be shown briefly. More details can be found in [1].

In the multimodal theory, the velocity potential will be decomposed into two parts. The first part incorporates the Neumann boundary conditions due to the cage motions, which are associated with the so-called Stokes-Joukowski potentials. The second part consists of a linear superposition of an infinite number of natural modes. The generalized coordinates for the natural modes are the unknowns, which need to be solved in either the time-domain, or the frequencydomain if possible. The sloshing natural modes determine the velocity potential distribution in space $\phi(x, y, z)$. The generalized coordinates denote the time-dependent component corresponding to each mode.

\subsection{Basis of the multimodal theory}

Tank-fixed coordinate system The coordinate system for the closed fish cage will be introduced. For boundaryvalue problem to be solved, the multimodal theory will be formulated in a tank-fixed coordinate system (Fig. 2). The model for the floating cylindrical fish cage here is based on a cage filled with liquid. The origin of the coordinate system is located at $\mathrm{O}$, which is the geometrical center of the mean free surface $\Sigma_{0} \cdot Q_{0}$ is the cage volume that is bounded by the mean free surface, $\Sigma_{0}$, and the mean wetted cage surface, $\mathrm{S}_{0}$.

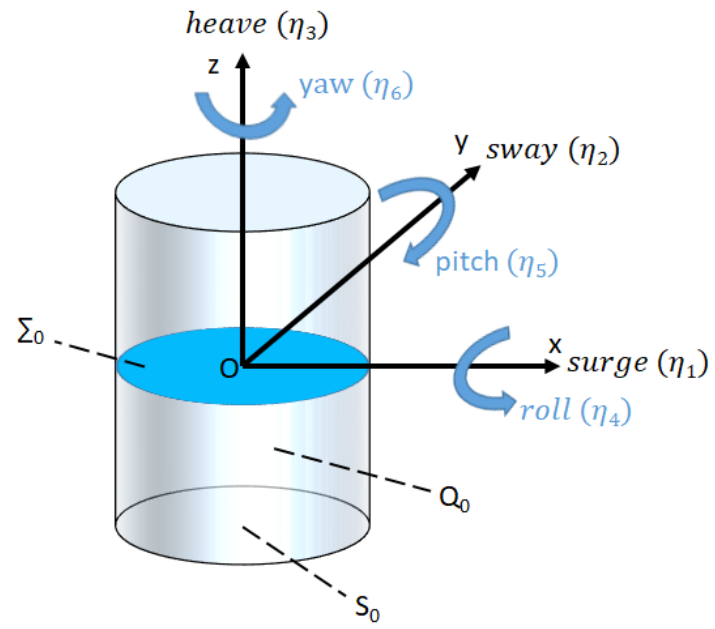

FIGURE 2: SKETCH OF THE CAGE WITH SIX DEGREES OF FREEDOM

As the cage is axisymmetric, the tank-fixed Cartesian coordinate system will be transferred into the cylindrical coordinate system $(r, \theta, z)$.

Laplace equation In potential flow theory, the Laplace equation serves as the governing equation. In the cylindrical coordinate system $(r, \theta, z)$, the Laplace equation is:

$$
\frac{\partial^{2} \phi}{\partial \mathrm{r}^{2}}+\frac{1}{\mathrm{r}} \frac{\partial \phi}{\partial \mathrm{r}}+\frac{1}{\mathrm{r}^{2}} \frac{\partial^{2} \phi}{\partial \theta^{2}}+\frac{\partial^{2} \phi}{\partial \mathrm{z}^{2}}=0
$$

Body boundary condition The body boundary condition ensures that flow is not able to travel across the cage surface. The body boundary condition can be expressed as:

$$
\frac{\partial \phi}{\partial \mathrm{n}}=\mathrm{v} \cdot \mathrm{n}=\mathrm{v}_{\mathrm{O}} \cdot \mathrm{n}+\omega \cdot[\mathrm{r} \times \mathrm{n}]
$$

where $\mathrm{n}$ is the normal vector on body surface, $\mathrm{v}_{\mathrm{O}}$ is the translatory velocity of the cage at the origin $\mathrm{O}, \omega$ is the angular velocity of the cage around the origin, and $r$ is the position vector, such that $r=\mathrm{xe}_{1}+\mathrm{ye}_{2}+\mathrm{ze}_{3}$ denotes a 
point on the body surface. Here $\mathrm{e}_{1}, \mathrm{e}_{2}$ and $\mathrm{e}_{3}$ are respectively the unit vectors along the $\mathrm{x}-, \mathrm{y}$ - and $\mathrm{z}$-axis of the tank-fixed coordinate system.

Dynamic free-surface condition In the dynamic freesurface condition, the pressure in the liquid at the free surface is equal to the atmospheric pressure. Thus, this boundary condition is:

$$
\frac{\partial \phi}{\partial \mathrm{t}}+\frac{1}{2}(\nabla \phi)^{2}-\left(\mathrm{v}_{\mathrm{O}}+\omega \times \mathrm{r}\right) \cdot \nabla \phi+\mathrm{U}_{\mathrm{g}}=0 \quad \text { on } \Sigma_{0},
$$

where the gravity potential $U_{g}=-g \cdot r=-g_{1} x-$ $\mathrm{g}_{2} \mathrm{y}-\mathrm{g}_{3} \mathrm{z}, \Sigma_{0}$ is the free surface. Here the atmospheric pressure has been set to zero, as this will not influence the hydrodynamic analysis. The acceleration due to gravity is $\mathrm{g}=\left(\mathrm{g}_{1}, \mathrm{~g}_{2}, \mathrm{~g}_{3}\right)$, which is equal to $(0,0,-\mathrm{g})$ when the tank does not have any angular motions.

Kinematic free-surface condition On the free surface, the fluid particle has to remain on the free surface. Thus, the kinematic free surface condition is given by:

$\frac{\partial \phi}{\partial \mathrm{z}}-\frac{\partial \phi}{\partial \mathrm{x}} \frac{\partial \zeta}{\partial \mathrm{x}}-\frac{\partial \phi}{\partial \mathrm{y}} \frac{\partial \zeta}{\partial \mathrm{y}}=\left(\mathrm{v}_{\mathrm{O}}+\omega \times \mathrm{r}\right) \cdot\left(-\frac{\partial \zeta}{\partial \mathrm{x}},-\frac{\partial \zeta}{\partial \mathrm{y}}, 1\right)+\frac{\partial \zeta}{\partial \mathrm{t}^{\prime}}$

where $\zeta$ is the free surface elevation.

\subsection{Natural frequencies and modes for upright circular cylindrical cage}

The natural frequencies and corresponding natural modes can be solved without considering any excitation. No cage excitation means that there are no cage motions. Therefore, the flow velocity potential $\phi$, satisfies $\partial \phi / \partial \mathrm{n}=0$ on $\mathrm{S}_{0}$. The solutions for the velocity potential and wave elevations need to satisfy the rest of the linearized boundary conditions. In this case, the natural sloshing modes can be expressed as

$\varphi(\mathrm{r}, \theta, \mathrm{z})=J_{m}\left(\mathrm{l}_{\mathrm{m}, \mathrm{j}} \frac{\mathrm{r}}{\mathrm{R}_{0}}\right) \frac{\cosh \left(\mathrm{\iota}_{\mathrm{m}, \mathrm{j}}(\mathrm{z}+\mathrm{h}) / \mathrm{R}_{0}\right)}{\cosh \left(\mathrm{\iota}_{\mathrm{m}, \mathrm{j}} \mathrm{h} / \mathrm{R}_{0}\right)}\left\{\begin{array}{l}\cos (m \theta) \\ \sin (m \theta)\end{array}\right.$,

where $\mathrm{J}_{\mathrm{m}}$ is the Bessel function of first kind with $m-$ th order, $j$ is the integer which represents the mode number, $\mathrm{I}_{\mathrm{m}, \mathrm{j}}$ is the root of $\mathrm{J}_{\mathrm{m}}^{\prime}\left(\mathrm{I}_{\mathrm{m}, \mathrm{j}}=0\right)$, and $\mathrm{h}$ and $\mathrm{R}_{0}$ represent the water depth and radius of the cage, respectively. The corresponding surface wave elevation patterns of natural modes $f(r, \theta)$ are defined as by substituting $z=0$ into Eq. 5:

$1,2, \ldots$,

$$
\mathrm{f}(\mathrm{r}, \theta)=\mathrm{J}_{\mathrm{m}}\left(\mathrm{t}_{\mathrm{m}, \mathrm{j}} \frac{\mathrm{r}}{\mathrm{R}_{0}}\right) \cdot\left\{\begin{array}{l}
\cos (m \theta) \\
\sin (m \theta)
\end{array}, m=0,1, \ldots ; j=\right.
$$

As can be seen in Eq. 5 and Eq. 6, the different natural sloshing modes solutions are indexed by integer indices $m$ and $j$. The natural frequencies $\sigma_{\mathrm{m}, \mathrm{j}}$ corresponding to each mode can then be written as

$\sigma_{m, j}^{2}=\left(g / R_{0}\right) \iota_{m, j} \tanh \left(\iota_{m, j} h / R_{0}\right), m=0,1, \ldots ; j=1,2, \ldots$,

\subsection{Nonlinear multimodal equations for circular cylinder}

For the natural mode solutions, it has been assumed that there is no excitation of the cage. The cage under excitation will now be studied, which means that the non-trivial body boundary condition and free surface conditions need to be considered. The multimodal theory denotes the velocity potential and free surface elevation by the summation of the infinite number of products between natural sloshing modes and generalized coordinates. Recalling the motions of the cage in Fig. 2, adjusting the velocity potential to satisfy the body boundary condition, Eq. 2 and the governing equation, Eq. 1, the total velocity potential may be expanded as:

$$
\begin{aligned}
& \Phi(\mathrm{x}, \mathrm{y}, \mathrm{z}, \mathrm{t})=\mathrm{v}_{\mathrm{O}}(\mathrm{t}) \cdot \mathrm{r}+\omega(\mathrm{t}) \cdot \Omega_{0}(\mathrm{x}, \mathrm{y}, \mathrm{z})+ \\
& \sum_{\mathrm{j}=1}^{\infty} \mathrm{R}_{\mathrm{j}}(\mathrm{t}) \varphi_{\mathrm{j}}(\mathrm{x}, \mathrm{y}, \mathrm{z})
\end{aligned}
$$

where $\varphi_{j}$ is the $j$-th natural sloshing mode defined in the previous section, and $\Omega_{0}(\mathrm{x}, \mathrm{y}, \mathrm{z})$ is the so-called StokesJoukowski potential that is associated with the angular motions of the cage, when both the mean body surface and the mean free surface boundaries are assumed to be solid. The potentials due to rigid body motions are $\mathrm{v}_{\mathrm{O}}(\mathrm{t}) \cdot \mathrm{r}$ and $\omega(\mathrm{t})$. $\Omega_{0}(\mathrm{x}, \mathrm{y}, \mathrm{z})$, which satisfy the Laplace equation, Eq. 1 , and body boundary condition, Eq. 2. $\mathrm{R}_{\mathrm{j}}(\mathrm{t})$ is the so-called generalized coordinate of the natural sloshing modes. The free surface elevation is given by

$\zeta(x, y, t)=\sum_{j=1}^{\infty} \beta_{j}(t) \varphi_{j}(x, y, 0)=\sum_{j=1}^{\infty} \beta_{j}(t) f_{j}(x, y)$,

where $\beta_{j}(t)$ is also the generalized coordinate for expanding the free surface elevation as a series in terms of the natural sloshing modes.

Substituting Eq. 8 and Eq. 9 into the dynamic and kinematic free surface boundary conditions (Eq. 3 and Eq.4), the solution of the generalized coordinates can be derived. Since the free-surface conditions are fully nonlinear, they are satisfied on the instantaneous position of the free surface. The generalized coordinates $\beta_{\mathrm{j}}, \mathrm{j}=1, \ldots, \backslash$ infity are fully coupled. Thus, the Moiseeve ordering was applied for simplifying the general solution of the multimodal theory. It is applied with two primary excited modes and secondary 
modes. The secondary modes are related to modes with $m=$ 0 and $m=2$ while the third-order modes are associated with $m=3$. In summary, the ordering of the generalized coordinates $\beta_{j}$ and $R_{j}$ can be expressed as:

$\beta_{1,1, \mathrm{k}} \sim \mathrm{R}_{1,1, \mathrm{k}} \sim \varepsilon^{1 / 3}$,

$\beta_{0, \mathrm{j}} \sim \mathrm{R}_{0,1} \sim \beta_{2, \mathrm{j}, \mathrm{k}} \sim \mathrm{R}_{2, \mathrm{j}, \mathrm{k}} \sim \varepsilon^{2 / 3}$,

$\beta_{3, \mathrm{j}, \mathrm{k}} \sim \mathrm{R}_{3, \mathrm{j}, \mathrm{k}} \sim \varepsilon, \quad \mathrm{k}=1,2 ; \quad \mathrm{j}=1,2, \ldots$,

where $k$ is denoted by 1 for the cosine term and 2 for the sine term in Eq. 5 and Eq. $6, \varepsilon$ is the parameter indicating the smallness of the excitation amplitude. The ordering here is different from the Stokes expansion that is used in the weakly nonlinear theories for external water waves, where $\varepsilon^{1}, \varepsilon^{2}$ and $\varepsilon^{3}$ represent first order, second order, and third order terms, respectively.

As can be seen in Eq. 10, the modal system has an infinite number of nonlinear equations. However, Chernova and Lukovsky [11] have proved that the second order modes that contribute to the cylindrical tank, are mainly based on three particular modes: $(0,1),(2,1,1)$ and $(2,1,2)$. It should be mentioned that $m=0$ in the mode $(0,1)$, which leads to the nonzero natural mode including a cosine term $(k=1)$ in Eq.8. The contributions of the higher modes $(3, j, k)$ are much less. Therefore, the other second order modes $(0, j)$ and $(2, j, k)$ and the higher modes $(3, j, k)$ are negligible. All the geometric dimensions are scaled by the radius $\mathrm{R}_{0}$. Thus, the multimodal method will couple the first and second order modes as:

$\mathrm{p}_{1}=\beta_{1,1,1}, \quad \mathrm{r}_{1}=\beta_{1,1,2}, \quad \mathrm{p}_{0}=\beta_{0,1}$,

$\mathrm{p}_{2}=\beta_{2,1,1}, \quad \mathrm{r}_{2}=\beta_{2,1,2}$,

Chernova and Lukovsky [11] have derived the modal equations with these five modes in Eq. 11 for a cylindrical cage as:

$$
\begin{aligned}
\ddot{p_{1}}+\sigma_{1}^{2} p_{1}+d_{1}^{*} & p_{1}\left(p_{1} \ddot{p_{1}}+\dot{p}_{1}^{2}+r_{1} \ddot{r_{1}}+\dot{r}_{1}^{2}\right) \\
& +d_{2}^{*}\left(r_{1}^{2} \ddot{p_{1}}+2 r_{1} r_{1} \ddot{p_{1}}-r_{1} p_{1} \ddot{r_{1}}-2 p_{1} r_{1}^{2}\right) \\
& +d_{3}^{*}\left(p_{2} \ddot{p_{1}}+r_{2} \ddot{r_{1}}+r_{1} \dot{r_{2}}+p_{1} \dot{p_{2}}\right) \\
& -d_{4}^{*}\left(p_{1} \ddot{p_{2}}+r_{1} \ddot{r_{2}}\right)+d_{5}^{*}\left(p_{0} \ddot{p_{1}}+p_{1} \dot{p_{0}}\right) \\
& +d_{6}^{*} p_{1} \ddot{p_{0}} \\
& =-P_{1}\left[\ddot{\eta_{1}}(t) / R_{0}-g \eta_{5}(t) / R_{0}-\overline{S_{1}} \ddot{\eta_{5}}(t)\right] \\
\ddot{r_{1}}+\sigma_{1}^{2} r_{1}+d_{1}^{*} & r_{1}\left(r_{1} \ddot{r_{1}}+r_{1}^{2}+p_{1} \ddot{p_{1}}+\dot{p}_{1}^{2}\right) \\
& +d_{2}^{*}\left(p_{1}^{2} \ddot{r_{1}}+2 p_{1} r_{1} \ddot{p_{1}}-r_{1} p_{1} \ddot{p_{1}}-2 r_{1} p_{1}^{2}\right) \\
& -d_{3}^{*}\left(p_{2} \ddot{r_{1}}-r_{2} \ddot{p_{1}}+r_{1} \dot{p_{2}}-p_{1} \dot{r_{2}}\right) \\
& +d_{4}^{*}\left(r_{1} \ddot{p_{2}}-p_{1} \ddot{r_{2}}\right)+d_{5}^{*}\left(p_{0} \ddot{r_{1}}+r_{1} \dot{p_{0}}\right) \\
& +d_{6}^{*} r_{1} \ddot{p_{0}} \\
& =-P_{1}\left[\ddot{\eta_{2}}(t) / R_{0}+g \eta_{4}(t) / R_{0}+\overline{S_{1}} \ddot{\eta_{4}}(t)\right] \\
\ddot{p_{0}}+\sigma_{0}^{2} p_{0}+d_{10}^{*} & \left(r_{1} \ddot{r_{1}}+p_{1} \ddot{p_{1}}\right)+d_{8}^{*}\left(\dot{r_{1}^{2}}+\dot{p}_{1}^{2}\right)=0
\end{aligned}
$$

$\ddot{p_{2}}+\sigma_{2}^{2} \mathrm{p}_{2}+\mathrm{d}_{9}^{*}\left(\mathrm{r}_{1} \ddot{\mathrm{r}_{1}}-\mathrm{p}_{1} \ddot{\mathrm{p}_{1}}\right)+\mathrm{d}_{7}^{*}\left(\dot{\mathrm{r}}_{1}^{2}-\dot{\mathrm{p}}_{1}^{2}\right)=0$

$\ddot{r_{2}}+\sigma_{2}^{2} r_{2}-d_{9}^{*}\left(r_{1} \ddot{p_{1}}+p_{1} \ddot{r_{1}}\right)-2 d_{7}^{*} \dot{r_{1}} \dot{p_{1}}=0$

(12)

where $\eta_{j}$ are the motions of the cage shown in Fig. 2 . The coefficients $\mathrm{P}_{1}$ and $\overline{\mathrm{S}_{1}}=\mathrm{S}_{1} / \mathrm{R}_{0}$ are defined as

$\mathrm{P}_{1}=\frac{2 \mathrm{t}_{1,1} \tanh \left(\mathrm{t}_{1,1} \mathrm{~h} / \mathrm{R}_{0}\right)}{\mathrm{t}_{1,1}^{2}-1}$

$\overline{S_{1}}=\frac{2 \tanh \left(\mathrm{L}_{1,1} \mathrm{~h} / 2 \mathrm{R}_{0}\right)}{\mathrm{I}_{1,1}}$.

The natural frequency corresponding to each mode can be calculated by Eq. 7. The hydrodynamic coefficients $d_{t}^{*}$ are tabulated in [11] as functions of the ratio $h / R_{0}$.

Either the ODE45 solver or the ODE15s solver in MATLAB can be applied in order to solve the differential equations. ODE15s is able to solve problems with a mass matrix that is singular, known as differential-algebraic equations. Therefore, the ODE15s solver better suited to solving the differential equations with stiff problems.

\subsection{Linear multimodal equations for circular cylinder}

Applying linearized boundary conditions, the linear sloshing multimodal equations can be derived. While similar to the nonlinear equations, the linear equations ignore all the nonlinear terms in Eq. 12:

$$
\begin{aligned}
& \beta_{1, j, 1}+\sigma_{1, j}^{2} \beta_{1, j, 1}=-P_{j}\left[\ddot{\eta}_{1}(t)-g \eta_{5}(t)-S_{j} \ddot{\eta}_{5}(t)\right], \\
& \beta_{1, j, 2}+\sigma_{1, j}^{2} \beta_{1, j, 2}=-P_{j}\left[\ddot{\eta}_{2}(t)+g \eta_{4}(t)+S_{j} \ddot{\eta}_{4}(t)\right],
\end{aligned}
$$

where Faltinsen and Timokha [1] have proved that the modes with $m=1$ are the only nonzero modes in a linear multimodal theory.

For both nonlinear and linear multimodal equations, Eq. 12 and Eq. 14, there is no damping because of the potential flow assumption. However, the damping exists inside the cage in reality because of, e.g. the boundary layer flow, internal slender structures or wave breaking. In this study, a linear damping term $2 \xi_{j} \sigma_{j} \dot{\beta}_{j}$ will be added to each modal equation, where $\$ \backslash x i \_j \$$ is the damping ratio. Therefore, the multimodal equations Eq. 12 and Eq. 14 take the following the general form:

$\beta_{1, j, k}+2 \xi_{j} \sigma_{i, j} \beta_{1, j, k}+\sigma_{i, j}^{2} \beta_{i, j, k}=K_{j}$

where $K_{j}$ represents the terms on the right hand sides of Eq. 12 and Eq. 14 induced by rigid body motion. Without the damping effect, the time domain solution of the generalized coordinates will have 'beating' oscillations in the time series at the resonant frequencies [1]. The amplitude of the solution 
increases linearly with time in a typical 'beating' oscillation. Therefore, in order to analyze the steady state solutions in the following sections, a very small damping ratio $\xi_{j}$ will be included in the modal equations to damp out the transient effect. The damping coefficients should be so small that their influence on the final steady-state solutions is negligible.

\subsection{Hydrodynamic force and moment}

In order to couple the sloshing effects with the exterior effects on the cylindrical cage, the hydrodynamic forces and moments caused by the sloshing need to be considered. The linearized momentum and force are derived by integrating the pressure around the cage surface. The desired expression for the resulting linear hydrodynamic force in terms of the introduced generalized coordinates is:

$\mathrm{F}(\mathrm{t})=-\mathrm{M}_{\mathrm{l}} \mathrm{ge} \mathrm{e}_{3}+\mathrm{e}_{1}\left[\mathrm{M}_{\mathrm{l}}\left(-\ddot{\eta_{1}}-\ddot{\eta_{5}} \mathrm{z}_{\mathrm{lC}}+\ddot{\eta}_{6} \mathrm{y}_{\mathrm{lC}}\right)-\right.$

$\left.\sum_{j=1}^{\infty} \lambda_{1 j} \ddot{\beta_{j}}\right]+e_{2}\left[M_{1}\left(-\ddot{\eta_{2}}-\ddot{\eta}_{6} x_{1 C_{0}}+\ddot{\eta}_{4} z_{1 C_{0}}\right)-\right.$

$\left.\sum_{\mathrm{j}=1}^{\infty} \lambda_{2 \mathrm{j}} \ddot{\beta_{\mathrm{J}}}\right]+\mathrm{e}_{3}\left[\mathrm{M}_{\mathrm{l}}\left(-\ddot{\eta_{3}}-\ddot{\eta_{4}} \mathrm{y}_{\mathrm{lC}}+\ddot{\eta}_{5} \mathrm{x}_{\mathrm{lC}}\right)\right]$,

where the forces in the $e_{1}, e_{2}$ and $e_{3}$ directions correspond to the surge, sway and heave forces. $\left(\mathrm{x}_{\mathrm{IC}_{0}}, \mathrm{y}_{\mathrm{IC}_{0}}, \mathrm{z}_{\mathrm{IC}_{0}}\right)$ is the position of the liquid mass center in the Oxyz system. The nonzero hydrodynamic coefficients are:

$\lambda_{1(1, \mathrm{j}, 1)}=\lambda_{2(1, \mathrm{j}, 2)}=\frac{\rho \pi R_{0}^{3}}{\mathrm{~L}_{1, \mathrm{j}}^{2}}$

The moment can be expressed as

$M_{\mathrm{O}}(\mathrm{t})=\left[\mathrm{M}_{1} \mathrm{~g}\left(\mathrm{x}_{\mathrm{lC}_{0}} \mathrm{e}_{2}-\mathrm{y}_{\mathrm{lC}} \mathrm{e}_{1}\right)\right]+\mathrm{e}_{1}\left[\mathrm{M}_{\mathrm{l}}\left(\mathrm{gz}_{\mathrm{lC}} \mathrm{\eta}_{0}+\right.\right.$

$\left.\mathrm{z}_{\mathrm{IC}_{0}} \ddot{\eta_{2}}-\mathrm{y}_{\mathrm{IC}_{0}} \ddot{\eta_{3}}\right)-\sum_{\mathrm{k}=4}^{6} \mathrm{~J}_{01(\mathrm{k}-3)}^{1} \ddot{\eta_{\mathrm{k}}}-\sum_{\mathrm{j}=1}^{\infty}\left(\mathrm{g} \lambda_{2 \mathrm{j}} \beta_{\mathrm{j}}+\right.$

$\left.\left.\lambda_{01 \mathrm{j}} \ddot{\beta_{\mathrm{J}}}\right)\right]+\mathrm{e}_{2}\left[\mathrm{M}_{\mathrm{l}}\left(\mathrm{gz}_{\mathrm{lC}} \eta_{5}+\mathrm{x}_{\mathrm{IC}_{0}} \ddot{\eta_{3}}-\mathrm{z}_{\mathrm{lC}_{0}} \ddot{\eta_{1}}\right)-\right.$

$\left.\sum_{\mathrm{k}=4}^{6} \mathrm{~J}_{02(\mathrm{k}-3)}^{1} \ddot{\eta}_{\mathrm{k}}-\sum_{\mathrm{j}=1}^{\infty}\left(\mathrm{g} \lambda_{1 \mathrm{j}} \beta_{\mathrm{j}}+\lambda_{02 \mathrm{j}} \ddot{\beta}_{\mathrm{J}}\right)\right]+$

$\mathrm{e}_{3}\left[\mathrm{M}_{\mathrm{l}}\left(-\mathrm{g}\left(\mathrm{x}_{\mathrm{IC}_{0}} \eta_{4}+\mathrm{y}_{\mathrm{lC}} \eta_{5}\right)+\mathrm{y}_{\mathrm{IC}_{0}} \ddot{\eta}_{1}-\mathrm{x}_{\mathrm{IC}_{0}} \ddot{\eta_{2}}\right)-\right.$

$\left.\sum_{\mathrm{k}=4}^{6} \mathrm{~J}_{03(\mathrm{k}-3)}^{1} \ddot{\eta_{\mathrm{k}}}-\sum_{\mathrm{j}=1}^{\infty} \lambda_{03 \mathrm{j}} \ddot{\beta_{\mathrm{j}}}\right]$,

where the momentum along the $\mathrm{e}_{1}, \mathrm{e}_{2}$ and $\mathrm{e}_{3}$ directions describe the moments about the $\mathrm{x}, \mathrm{y}$ and $\mathrm{z}$ axes. The nonzero hydrodynamic coefficients are:

$\lambda_{02(1, \mathrm{j}, 1)}=-\lambda_{01(1, \mathrm{j}, 2)}=-\frac{2 \pi \rho R_{0}^{4}}{\mathrm{\iota}_{1, \mathrm{j} \cdot}^{3}} \tanh \left(\frac{\iota_{1, j} h}{2 R_{0}}\right)$.

Furthermore, for the inertia tensor, there are only two non-zero diagonal elements. They are expressed as follows after a typo in the text book [1] is corrected.

$$
\begin{aligned}
& \mathrm{J}_{011}^{1}=\mathrm{J}_{022}^{1}=\rho \pi \mathrm{R}_{0}^{2}\left[\frac{1}{3} \mathrm{~h}^{3}-\frac{3}{4} \mathrm{hR}_{0}^{2}+\right. \\
& \left.16 \mathrm{R}_{0}^{3} \sum_{\mathrm{j}=1}^{\infty} \frac{\tanh \left(\mathrm{L}_{1, \mathrm{j}} \mathrm{h} / 2 \mathrm{R}_{0}\right)}{\mathrm{l}_{1, \mathrm{j}}^{3}\left(\mathrm{~L}_{1, \mathrm{j}}^{2}-1\right)}\right] .
\end{aligned}
$$

The above equations are presented for linear forces and moments. The nonlinear versions of the formulas are similar but slightly more complex, and these can be found in [1].

\section{Coupling process of exterior and interior wave effects}

As the interior liquid sloshing problem can be solved by the single-dominant multimodal approach as explained in Section 2, the motion of the closed fish cage in waves can be analyzed with consideration of coupled sloshing in the tank. The coupled motion is based on the Impulse Response Function derived from Cummins equation [2]:

$$
\begin{aligned}
& \left(M_{j k}+A_{j k}^{t}+A_{j k}^{\infty}\right) \ddot{\eta}_{k}(t)+\int_{-\infty}^{t} K_{j k}(t-\tau) \dot{\eta_{k}}(\tau) d \tau+ \\
& C_{j k} \eta_{k}(t)=\int_{-\infty}^{\infty} K_{j D}(t-\tau) \zeta_{0}(\tau) d \tau+F_{\text {sloshing }}^{r}(t)
\end{aligned}
$$

where $M_{j k}$ is the mass matirx of the cage, $A_{j k}^{t}$ and $\mathrm{F}_{\text {sloshing }}^{\mathrm{r}}$ are the terms induced by sloshing effect which will be discussed in the following sections. $\mathrm{A}^{\infty}$ is the added mass induced by a wave with infinite frequency, $C_{j k}$ is the hydrostatic matrix, and $\zeta_{0}$ is the incident wave elevation at the center of the structure. $\mathrm{K}_{\mathrm{jk}}$ and $\mathrm{K}_{\mathrm{jD}}$ are the impulseresponse functions for the radiation force and diffraction force, respectively. $K_{j k}$ and $K_{j D}$ are linked with frequencydomain coefficients as:

$$
\begin{aligned}
& B_{j k}=\int_{0}^{\infty} K_{j k}(t) \cos \omega t d t \\
& X_{j}=\int_{-\infty}^{\infty} K_{j D}(t) e^{-i \omega t} d t
\end{aligned}
$$

where $B_{j k}$ is the damping matrix, $X_{j}$ is the diffraction force in frequency-domain, and $\omega$ is the wave frequency. $\mathrm{K}_{\mathrm{jk}}$ and $\mathrm{K}_{\mathrm{jD}}$ can therefore be calculated using the Inverse Fast Fourier Transformation (IFFT).

\subsection{Exterior wave hydrodynamics for the upright circular cylindrical cage}

The aforementioned frequency domain hydrodynamic coefficients $A^{\infty}, B_{j k}$ and $X_{j}$ can all be obtained from WAMIT. However, the WAMIT results are in the frequencydomain, while the final simulator should operate in the timedomain. For this purpose, the MATLAB script package 
DTUMotionSimulator will be applied to carry out the convolution integrals and solve the time-domain motion equations in Eq. 21.

WAMIT simulation WAMIT is used to calculate the interaction between floating bodies and waves, which is based on the linear wave-structure interaction theory to solve the wave diffraction and radiation problems in the frequency domain. An example of the panel model in WAMIT is shown in Fig. 3.

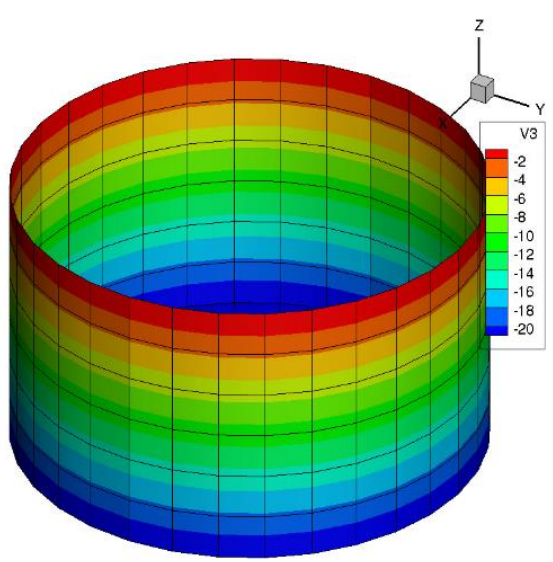

\section{FIGURE 3: INPUT PANEL MODEL FOR WAMIT}

DTUMotionSimulator DTUMotionSimulator is used to simulate the linear and nonlinear response of a floating marine structure in ocean waves. Nonlinear loads, such as sloshing loads and mooring loads, can be included on the right hand side of the Cummins equations. The script solves the equations of motion in the time domain to simulate a floating structure interacting with a prescribed time series of ocean wave elevation. The hydrodynamic coefficients for the body are read in from WAMIT output files and used together with an input wave elevation time series to integrate the motion equations forward in time using the classical explicit RungeKutta $(4,4)$ scheme. The process is shown in Fig. 4 below.

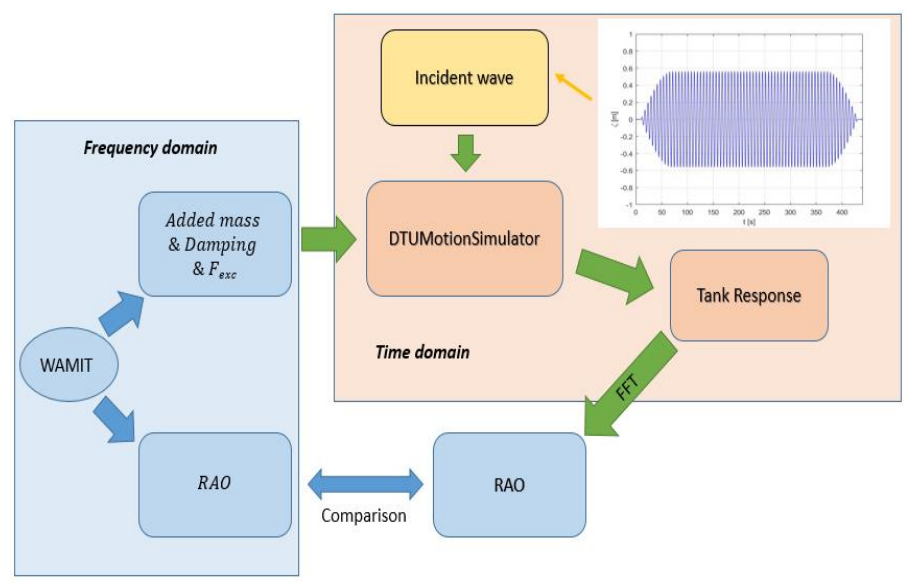

FIGURE 4: THE PROGRESS OF CAGE RESPONSE CALCULATION

The RAO in Fig. 4 is the response amplitude operator which denotes the ratio of the response amplitude to the wave amplitude. The calculation of the RAO from the time domain results is obtained, through Fast Fourier Transformation for the steady-state part of the cage responses, which will be used for the verification of the coupled solver in the time domain. WAMIT can also generate the RAO from a frequency-domain analysis. When the incident waves are asymptotically small, the frequency-domain results from WAMIT are regarded as a good reference to verify the present time domain results.

At the beginning of the time domain simulation, zero cage movement (displacement $\eta_{j}$, velocity $\dot{\eta}_{j}$ and acceleration $\left.\ddot{\eta_{\mathrm{J}}}\right)$ and zero sloshing properties $\left(\beta_{\mathrm{j}}, \dot{\beta_{\mathrm{J}}}\right.$ and $\left.\ddot{\beta}_{\mathrm{J}}\right)$ are used as initial conditions. Using the standard 4-stage Runge-Kutta method, the cage motion for the next time step can be simulated, which can be regarded as excitation for interior liquid sloshing. The loads induced by sloshing are obtained from the multimodal theory, which will be used in the coupled motion equations in Eq. 21. Using this approach, the cage motion at a new time step can be obtained. Running the loop, the cage motions and loads can be calculated in the time-domain.

Recalling Eq. 21, the terms $A^{t}$ and $F_{\text {sloshing are }}^{r}$ induced by sloshing. The reason of separating the sloshing loads into two parts, is that the stability of the explicit Runge Kutta method can be improved when the terms associated with accelerations are moved to the left hand side of Eq. 21. From Eq. 16 and Eq. 18, the sloshing loads are equal to $F_{j}=$ $-A^{t} \ddot{\eta}_{j}+F_{\text {sloshing. Here }}^{r} A^{t}$ is defined as: 
$\left[\begin{array}{cccccc}M_{l} & 0 & 0 & 0 & M_{l} z_{l C_{0}} & 0 \\ 0 & M_{l} & 0 & -M_{l} z_{l C_{0}} & 0 & 0 \\ 0 & 0 & M_{l} & 0 & 0 & 0 \\ 0 & -M_{l} z_{l C_{0}} & 0 & J_{011}^{1} & 0 & 0 \\ M_{l} z_{l C_{0}} & 0 & 0 & 0 & J_{022}^{1} & 0 \\ 0 & 0 & 0 & 0 & 0 & 0\end{array}\right]=\mathrm{A}^{\mathrm{t}}$

(23)

where $\mathrm{J}_{011}^{1}$ and $\mathrm{J}_{022}^{1}$ are the inertia tensor defined in Eq. 20. $\mathrm{Z}_{\mathrm{IC}}$ is the position of liquid mass center as mentioned in Eq. 16, while in this case $\mathrm{z}_{\mathrm{IC}_{\mathrm{O}}}=-\mathrm{h} / 2$.

\section{Verification and swirling wave analysis}

The geometry and the loading condition of the upright circular cylindrical cage that will be considered are listed in Table 1 (Dimension data from [3]). The natural frequency of the first mode, calculated by Eq. 7 together with the cage dimension in Table 1 , is $\sigma_{1}=0.9339 \mathrm{rad}^{-1}$.

Table 1: CAGE GEOMETRY AND LOADING CONDITION

\begin{tabular}{cccc}
\hline Item & Symbol & Value & Unit \\
\hline Radius & $\mathrm{R}_{0}$ & 20 & $\mathrm{~m}$ \\
Draft & $\mathrm{h}$ & 22 & $\mathrm{~m}$ \\
Wave depth & $\mathrm{H}_{\mathrm{w}}$ & 60 & $\mathrm{~m}$ \\
Density & $\rho$ & 1000 & $\mathrm{~kg} / \mathrm{m}^{3}$ \\
Interior liquid damping & $\xi$ & 0.01 & \\
Excitation amplitude & $\eta_{\mathrm{ja}}$ & 0.1 & $\mathrm{~m}$ \\
Excitation frequency & $\omega_{\mathrm{j}}$ & 0.5 & $\mathrm{rad}^{-1}$ \\
\hline
\end{tabular}

\subsection{Verification of multimodal sloshing solution}

If the excitation frequency is far from the natural frequency of the cage, and the excitation amplitude is small enough, the nonlinear multimodal approach should give similar results to the linear multimodal method, because the nonlinear terms in Eq. 12 are negligibly small. For the nonlinear multimodal solution, five modes are involved in the coupled modal equations, which can contribute to the nonlinear simulation in Eq. 12. And it can be proved that, the value of the first two modes $(m=1)$ dominates all of the modes. One example is shown in Fig. 5.


FIGURE 5: GENERALIZED COORDINATES SOLUTION FROM NONLINEAR MULTIMODAL THEORY $\left(\eta_{1 \mathrm{a}}=0.1 \mathrm{~m} \& \omega_{1}=\right.$ $\left.0.5 \mathrm{rad}^{-1}\right)$

Fig. 5 confirms that the generalized coordinates of the first mode $\mathrm{p} 1$ is much higher than that for the other modes $\mathrm{p} 0$ and $\mathrm{p} 2$. The reason that $\mathrm{r} 1$ does not have a value, is that there is no excitation in the sway direction in this case. The two primary modes $\mathrm{p} 1$ and $\mathrm{r} 1$ in nonlinear multimodal equations are the same as the first modes $(1,1, k)$ of linear multimodal equations. Meanwhile, far from the resonant state, the first modes $m=1$ of the linear solution can also be proved to have the highest value among all the modes. Therefore, in the following comparison, only the first mode $(1,1, k)$ of the generalized coordinates will be selected for comparing. The comparison between the nonlinear and linear multimodal equations of the first mode $\mathrm{p} 1$ is shown in Fig. 6.

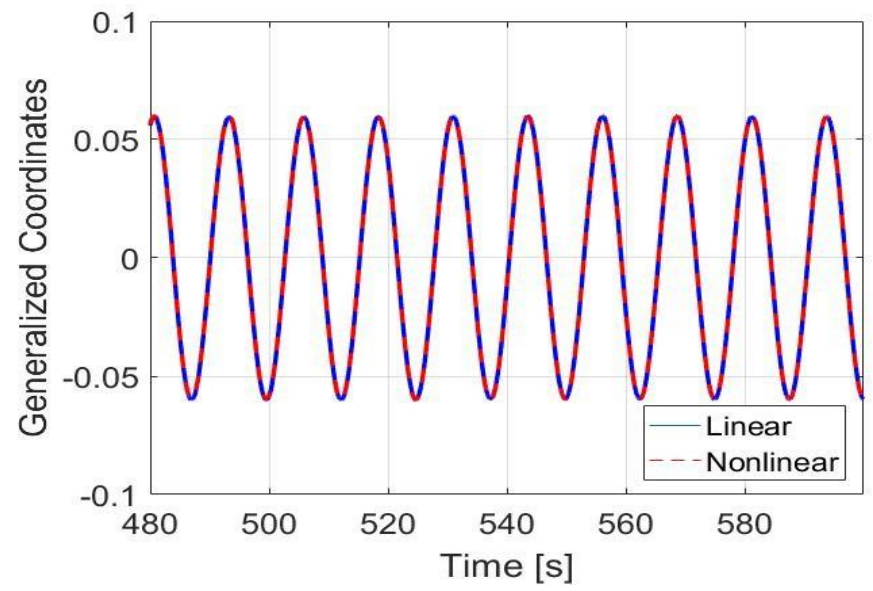

FIGURE 6: GENERALIZED COORDINATES VERIFICATION BETWEEN LINEAR AND NONLINEAR MULTIMODAL THEORY $\left(\eta_{1 \mathrm{a}}=0.1 \mathrm{~m} \& \omega_{1}=0.5 \mathrm{rad}^{-1}\right)$ 
Fig. 6 indicates that the generalized coordinate for the first natural mode in the nonlinear solution is almost the same as that of the linear solution when the excitation frequency is far from the resonant frequency and the excitation amplitude is small.

A verification for the linear solutions will be made by comparing with a linear analytical solution from [4]. The solutions provided by [4] are based on the linear steady state solution. Thus, to validate the linear multimodal solution, the damping ratio $\left(\xi_{j}=0.01\right)$ has been added as shown in Eq. 15 . Therefore, the transient effect will be damped out and the solution will reach the steady state because of linear damping term added into the modal equations. But it should be noted that the solutions provided by [4] have some printing errors. After some corrections, the free surface elevation and hydrodynamic force can be used for verification. by

The solution of the surface wave elevation in [4] is given

$$
\begin{aligned}
& \eta=\frac{\mathrm{X}_{0} \Omega^{2}}{\mathrm{~g}} \cos \theta \sin (\Omega \mathrm{t})[\mathrm{r}+ \\
& \left.\quad \sum_{\mathrm{n}=1}^{\infty} \frac{2 \mathrm{R}}{\left(\lambda_{1 \mathrm{n}}^{2}-1\right)} \frac{\Omega^{2}}{\left(\omega_{1 \mathrm{n}}^{2} \Omega^{2}\right)} \frac{\mathrm{J}_{1}\left(\lambda_{1 \mathrm{n}} \mathrm{r} / \mathrm{R}\right)}{\mathrm{J}_{1}\left(\lambda_{1 \mathrm{n}}\right)}\right]
\end{aligned}
$$

where $\lambda_{1 \mathrm{n}}$ are the roots of Bessel function, $\mathrm{X}_{0}$ and $\Omega$ are the excitation amplitude and frequency, respectively. Comparison of the wave elevation at a point $\left(x=R_{0}, \theta=\right.$ 0 ) between the present multimodal solution and the steadystate solution of [1] is shown in Fig. 7.

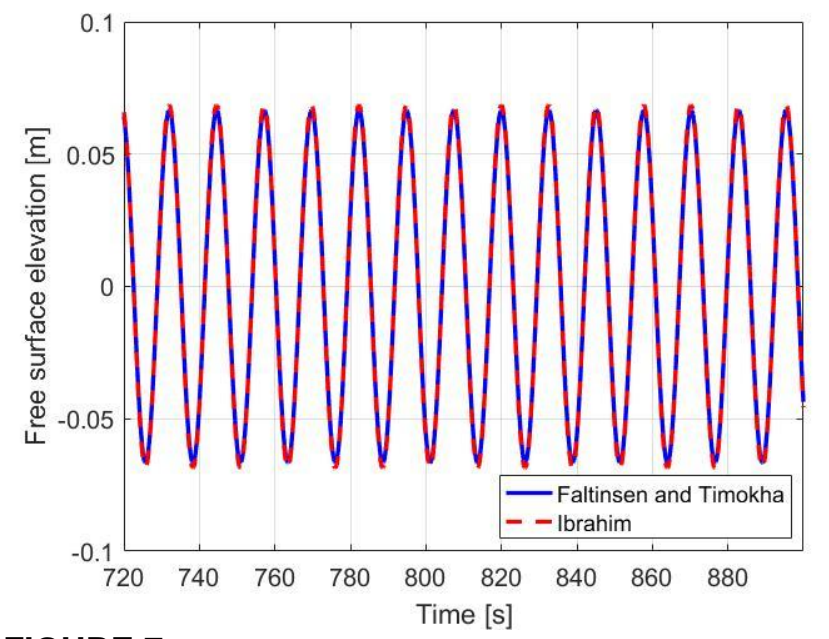

FIGURE 7: FREE SURFACE ELEVATION WITH ONLY SURGE EXCITATION $\left(\eta_{1 \mathrm{a}}=0.1 \mathrm{~m} \& \omega_{1}=0.5 \mathrm{rad}^{-1}\right)$.

It can be seen that the present multimodal result agrees very well with the that in [1]. It should be noted that the present multimodal results will not be exactly the same as the linear steady-state solution of [4]. The reason is that a small linear damping has been applied in the modal equations, while the damping is zero in [4]. However, one can see from the comparison that the very small damping ratio of 0.01 has very little effects when the time domain results have reached steady state values.

The force components acting on the cage wall and bottom are obtained by integrating the pressure over the corresponding area of the boundary. In a linear sloshing theory, the tank has only a surge force and a pitch moment around the $y$-axis. The force along the $\mathrm{x}$-axis is:

$$
\begin{aligned}
\mathrm{F}_{\mathrm{x}}=\mathrm{m}_{\mathrm{f}} \mathrm{X}_{0} \Omega^{2} \sin \Omega \mathrm{t} \times[1+ \\
\left.\sum_{\mathrm{n}=1}^{\infty} \frac{1}{\lambda_{1 \mathrm{n}} \mathrm{h}} \frac{2 \mathrm{R}}{\left(\lambda_{1 \mathrm{n}}^{2}-1\right)} \frac{\Omega^{2}}{\left(\omega_{1 \mathrm{n}}^{2}-\Omega^{2}\right)} \tanh \left(\lambda_{1 \mathrm{n}} \mathrm{h} / \mathrm{R}\right)\right],
\end{aligned}
$$

where $m_{f}=\rho \pi h R^{2}$ is the total mass of the fluid. The comparison of the force calculated from [1] and [4] is shown in Fig. 8. Similar with the free surface elevation, the steady state comparison shows relatively close values of the force (Fig. 8).

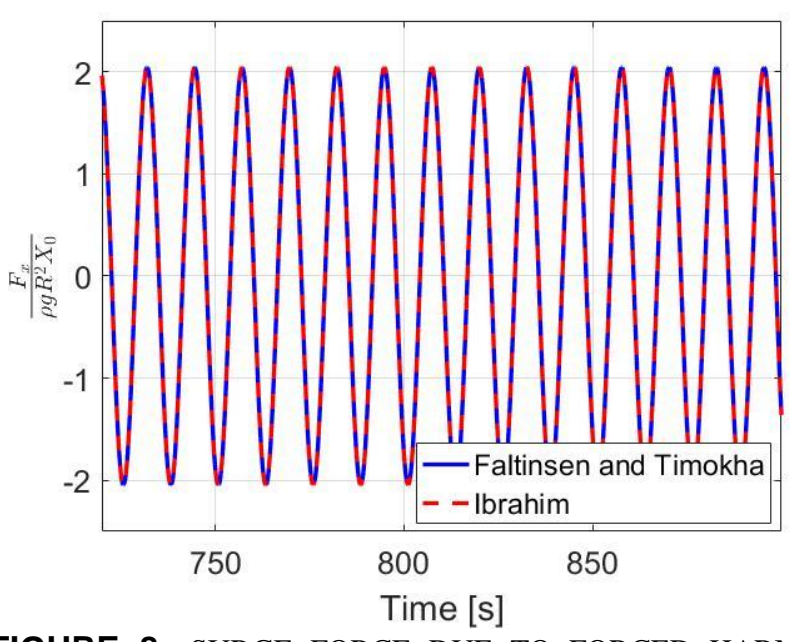

FIGURE 8: SURGE FORCE DUE TO FORCED HARMONIC SURGE MOTION $\left(\eta_{1 \mathrm{a}}=0.1 \mathrm{~m} \& \omega_{1}=0.5 \mathrm{rad}^{-1}\right)$.

Eq. 25 indicates that when the natural frequency equals the excitation frequency, the hydrodynamic forces due to sloshing should reach infinity. Indeed, with the sloshing solver, it is convenient to see that the value of force along the $\mathrm{x}$-axis will reach very large values every time when the excitation frequency reaches the natural frequency in each mode (Fig. 9). It should be mentioned that the properties in the figure are non-dimensional. The red points in Fig. 9 are the experimental data provided by 4 . For the results presented 
in Fig. 9, the draft to radius ratio is $h / R_{0}=2$. As can be seen in Fig. 9, when the excitation frequency is far from the natural frequencies and the excitation amplitude is very small, the linear solution is very accurate. However, when the excitation frequency is close to natural frequencies, the linear solution has inappropriate results for the sloshing responses as the results will reach very large values if no additional damping is included. This is not physical, and will not occur when a proper nonlinear theory is applied. In that case, the energy will be transferred from lower mode to higher mode. Because of this an infinite response will not occur when a proper nonlinear theory is applied.

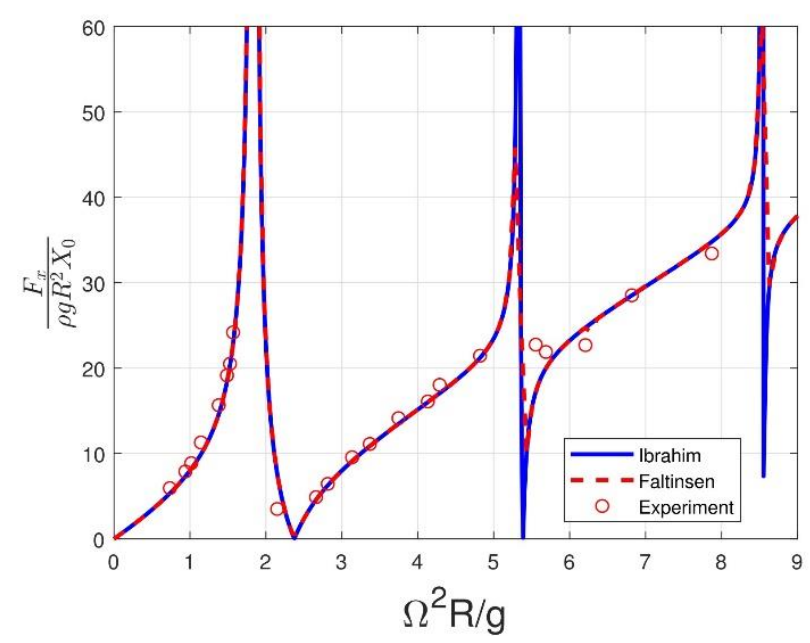

FIGURE 9 FORCE AMPLITUDE ALONG X-AXIS AS FUNCTION OF EXCITATION FREQUENCY FOR $h / R_{0}=2$. THE TANK IS UNDER FORCED HARMONIC MOTIONS IN SURGE.

\subsection{Simulator verification}

When the incident wave steepness is very small, so that the linear hydrodynamic coefficients are valid for the external hydrodynamic problem, the steady-state results of WAMIT can be used to verify the present coupled time-domain solver. To avoid drifting of the model in the horizontal plane, soft springs have been added to the cage in surge, sway and yaw.

Fig. 10 shows the comparison for surge RAOs between the present coupled model and WAMIT. ' RAO surge $_{\text {s. }}$ calculated by the linear solver' represents the present results applying a linear multimodal sloshing solver, i.e. all the nonlinear terms in the model equations Eq. 12 are ignored. ' $\mathrm{RAO}_{\text {surge }}$ calculated by the nonlinear solver' shows the results using the single-dominant multimodal method in the coupled time-domain solver. The wave steepness of the incident wave is $\delta=0.02$. It is seen that the present results based on the linear multimodal approach agree very well with WAMIT linear frequency results. Both the exterior and interior free surface have been modelled in WAMIT, thus the model in WAMIT is also a coupled model in the frequency domain. It is seen from Fig. 10 that, the nonlinear sloshing effects on the cage motion seem to be negligible for the wave steepness of 0.02 . The incident wave steepness has been further increased up to 0.2 to check the nonlinear sloshing effect. The results are compared with the WAMIT linear results and that for the wave steepness of 0.02 in Fig.11. The wave frequency was set to be the same for these two cases, but the high wave steepness will lead to high incident wave amplitude. For the studied cases, the results in Fig. 10 and Fig. 11 indicate that the wave steepness has little effect on the surge RAO.

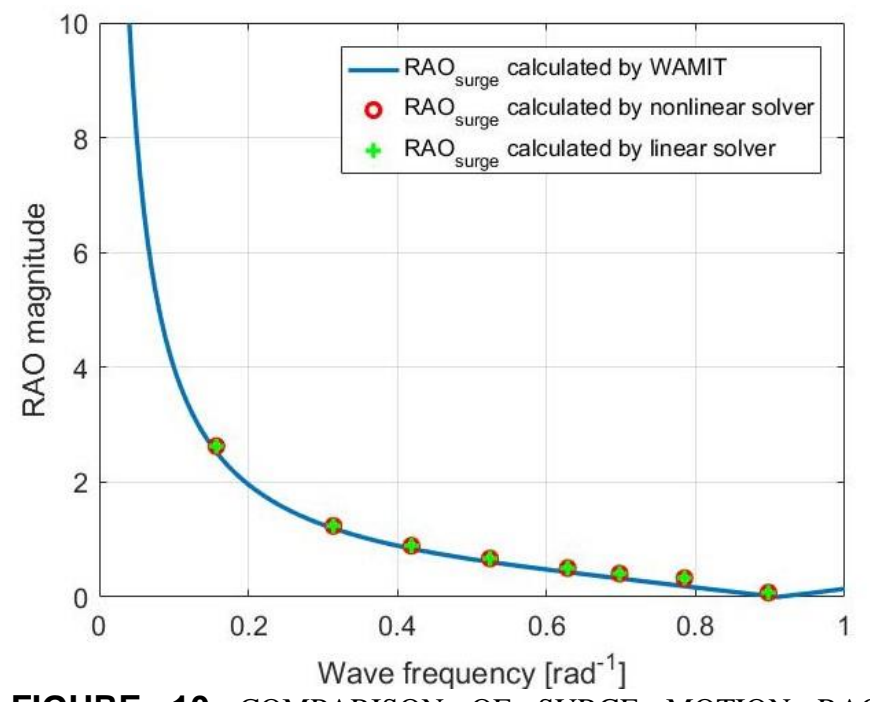

FIGURE 10 COMPARISON OF SURGE MOTION RAOS BETWEEN WAMIT AND PRESENT COUPLED TIME DOMAIN SOLVER WITH WAVE STEEPNESS 0.02. RESULTS BASED ON BOTH LINEAR AND NONLINEAR SLOSHING SOLUTIONS ARE CONSIDERED.



FIGURE 11 COMPARISON OF SURGE MOTION RAOS BETWEEN WAMIT AND PRESENT COUPLED TIME DOMAIN SOLVER. WAVE STEEPNESS 0.02 AND 0.2 ARE CONSIDERED IN THE PRESENT RESULTS. 


\subsection{Flow regimes from nonlinear free surface elevation}

From the nonlinear multimodal theory, the free surface elevation inside the cage can be simulated by Eq. 9. In contrast to the linear sloshing solution, the modes in the differential equations Eq. 12 have coupled which each other, meaning that the energy can be transferred from the first mode to the other modes. Considering a cage with surge motion only, the liquid inside the cage may have different wave regimes, namely a planar wave, a swirling wave and a chaos wave.

The planar and swirling waves are stable steady-state solutions of the nonlinear equations in Eq. 12. To trigger the swirling waves in the tank, a very small disturbance should be added as part of the initial conditions in the time domain solution of the modal equations. If steady state swirling waves are the possible solution to the nonlinear modal equations, the initial small disturbance will die out with time, while the steady state swirling waves are generated which do not decay with time. If no initial disturbance is included, the solution of Eq. 12 will always be planar waves. Those planar waves may be unstable solutions of the modal equations, as a tiny disturbance in the tank will destroy the solution and a stable steady-state swirling wave may be generated instead. In reality, disturbance is always presented as part of the natural process.

To distinguish the flow regimes, two probes have been set at two different horizontal locations with a $90^{\circ}$ differences in the angular direction, i.e. a point at $(r=R \quad \& \quad \theta=0)$ and $(r=R \& \theta=\pi / 2)$. The free surface elevation is measured when the liquid response has reached steady state. The phase planes of the wave elevation at the two locations for different possible flow regimes are shown in Figure 12.

In Fig. 12, the free surface elevation measured by one probe in the planar wave remains zero while the value measured by another probe continues to oscillate. The swirling wave in Fig. 12 can be considered as an analogy to the pendulum rotary motion. The range of the measured free surface elevation from each of the two probes is almost the same. The chaos wave in Fig. 12 represents an irregular wave. In this wave regime, there is are steady state wave motions in the upright circular cylindrical cage. Both of the amplitude and the frequency of the free surface elevation cannot be predicted, and they are dependent on the applied initial conditions.
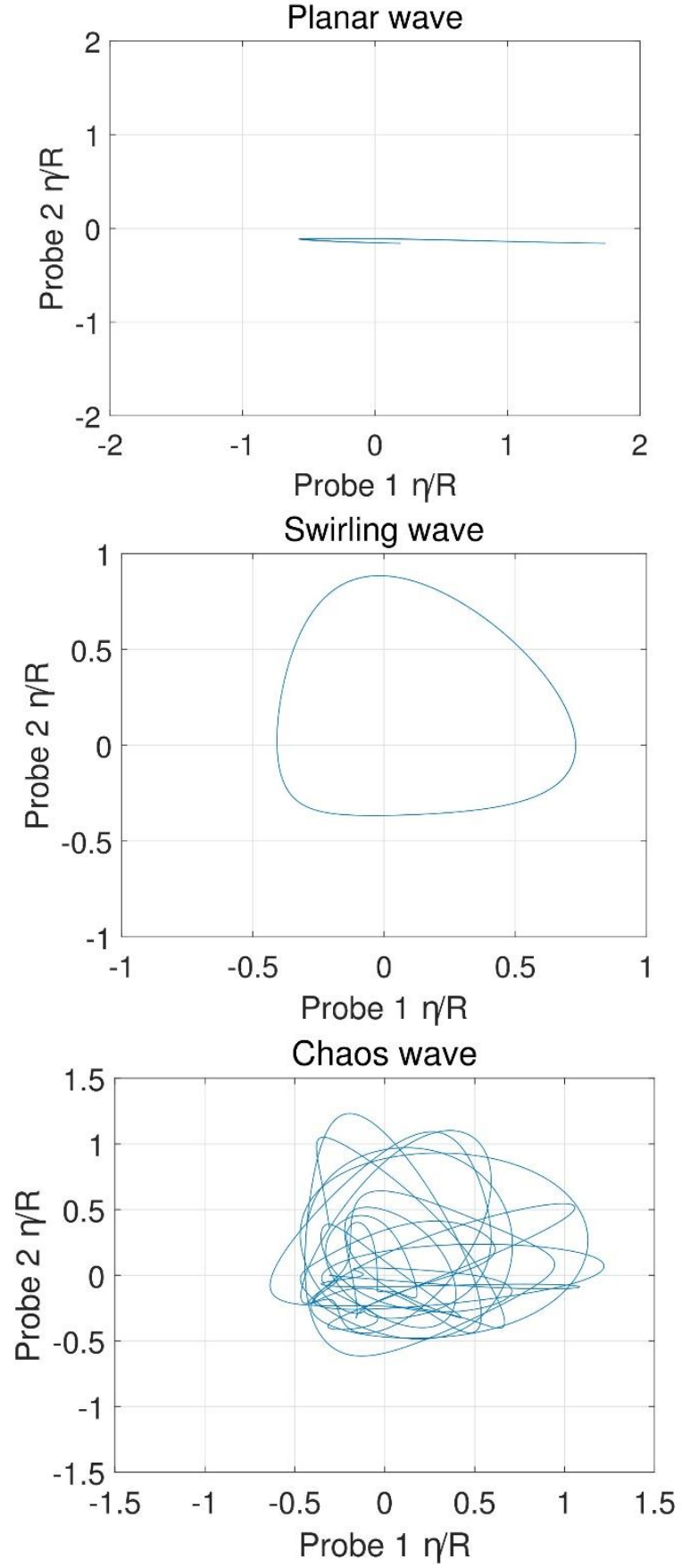

FIGURE 12 PHASE PLANE PLOTS FOR TYPICAL PLANAR WAVE, SWIRLING WAVE AND CHAOTIC WAVE.

By taking different combinations of excitation amplitude and excitation frequency, the bounds of the flow regimes could be identified in Fig. 13 . 


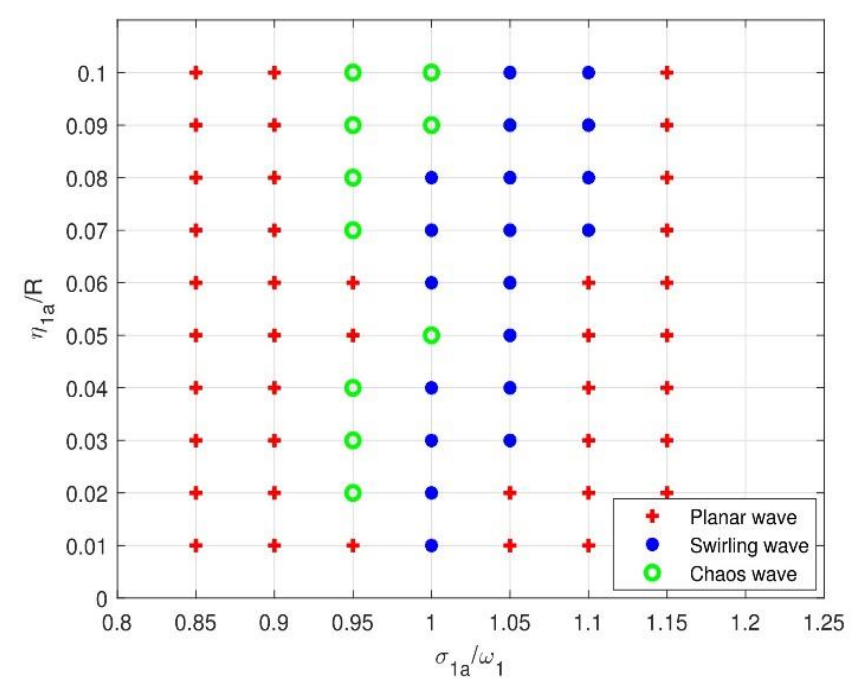

FIGURE 13 BOUND OF FLOW REGIMES $(\mathrm{h}=$ $22 \mathrm{~m}, \mathrm{R}=20 \mathrm{~m})$.

The swirling waves and chaos waves can only be found close to the resonant state. However, although the excitation frequencies are selected at the resonant region, the swirling waves and chaos waves do not occur exactly at the primary resonance as in Fig. 13. As the excitation motion that can generate swirling waves is specified, the swirling effect on the cage can be studied.

\subsection{Hydrodynamic loads induced by swirling waves}

Applying Eq. 16 and Eq. 18, the hydrodynamic loads can be calculated for planar waves and swirling waves. For this purpose, the excitation amplitude and frequency are chosen to excite swirling waves according to Fig. 13. However, with this excitation combination, the swirling wave will not be excited if no disturbance is added into the system, which means only the planar wave will be generated.

Considering only the hydrodynamic forces along the surge direction $\left(\mathrm{F}_{\mathrm{x}}\right)$ and the sway direction $\left(\mathrm{F}_{\mathrm{y}}\right)$, Fig. 14 and Fig. 15 contain the forces induced by planar waves and swirling waves, respectively. It should be mentioned that only the excitation along the surge direction is added into the system. The results in the figures indicate that, the hydrodynamic forces induced by swirling waves can be much more intense than those induced by planar waves. Meanwhile, the planar wave can not generate hydrodynamic force $F_{y}$ as shown in Fig. 14. This is easy to understand because there is no exciting energy along this direction. However, due to the swirling wave, the hydrodynamic force $\mathrm{F}_{\mathrm{y}}$ is generated. And $\mathrm{F}_{\mathrm{y}}$ will not vanish which means the wave keeps rotating inside the cage. The value of $F_{y}$ at the steady state period is still relatively large compared with $\mathrm{F}_{\mathrm{X}}$.
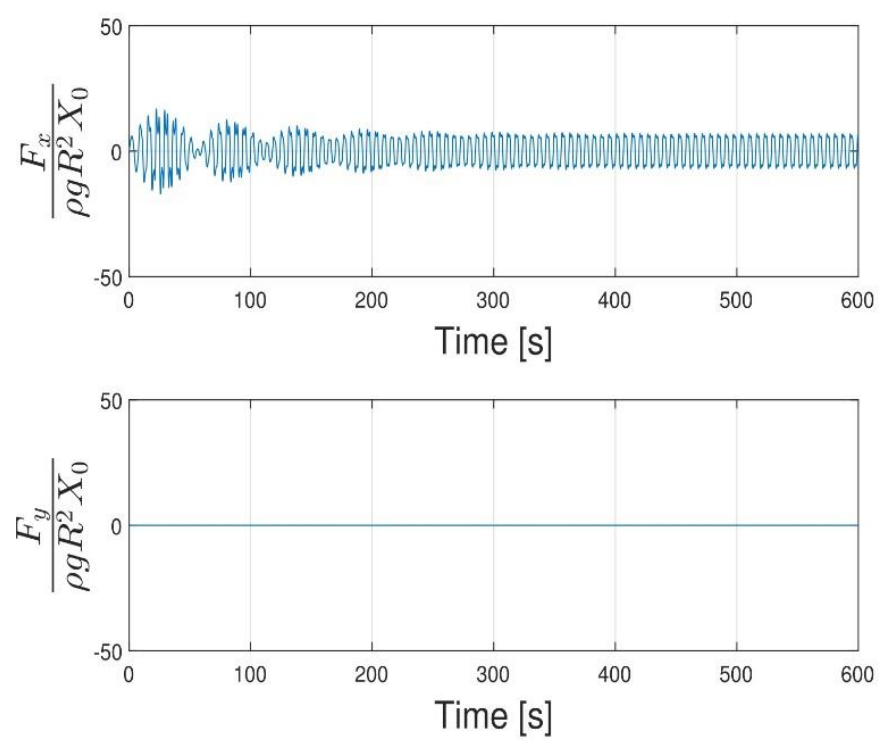

FIGURE 14 HYDRODYNAMIC FORCES IN SURGE AND SWAY DIRECTION FOR PLANAR WAVES $\left(\eta_{1 \mathrm{a}}=\right.$ $\left.0.05 R_{0} \& \omega_{1}=1.05 \sigma_{1}\right)$.
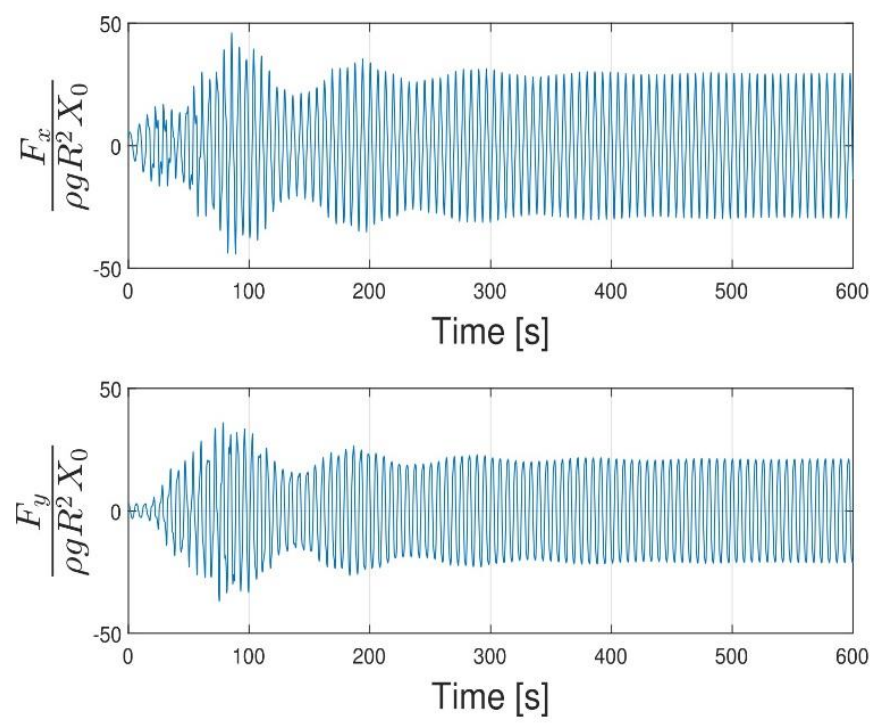

FIGURE 15 HYDRODYNAMIC FORCES IN SURGE AND SWAY DIRECTION FOR SWIRLING WAVES $\left(\eta_{1 \mathrm{a}}=\right.$ $\left.0.05 R_{0} \& \omega_{1}=1.05 \sigma_{1}\right)$.

\subsection{Swirling wave effect on closed fish cage}

The hydrodynamic loads in swirling waves have been proven to be very intense compared to the planar wave. As the motion of a cylindrical cage with a prescribed regular wave can be simulated now, the cage behavior coupled with the swirling wave generated inside the cage can be analyzed. The new properties of exterior waves are defined in Table 2. 
Table 2: WAVE PROPERTIES FOR ANALYZING SWIRLING WAVE EFFECT

\begin{tabular}{cc}
\hline Item & Property \\
\hline Incident wave frequency & $1.05 \sigma_{1}$ \\
Incident wave direction & $\mathrm{x}-$ \\
Disturbance & $0.005 \mathrm{R}_{0}$ \\
Disturbance direction & $\mathrm{y}-$ \\
Exterior damping ratio & 0.01 \\
Wave steepness & 0.4 \\
\hline
\end{tabular}

By adding disturbance in the simulator, the swirling wave inside the cage may be generated if the combination of the excitation frequency and amplitude meet certain criteria. If no disturbance is added, only planar waves can be observed in the numerical results, even though the planar waves are not stable in reality. Therefore, the swirling wave effect on the cage responses can be investigated by comparing the results with the case, where only planar waves in the cage are considered. The initial disturbance could induce a little sway motion which may further induce the force along the $y$ direction. And the force may enlarge the sway motion which generates the swirling wave at the end. Therefore, it is necessary to verify that the swirling wave is not induced by the combined cage motions in surge and sway. For this purpose, the sway and roll motions have been restrained in the time domain simulation as a starting point. In this case, the value of two primary generalized coordinates ( $\mathrm{p} 1$ and $\mathrm{r} 1$ ) are shown in Fig. 16. In Fig. 16, without sway and roll motions, $\mathrm{r} 1$ still has a similar value to $\mathrm{p} 1$. This means the sway and roll motions are not the direct cause of the swirling waves.
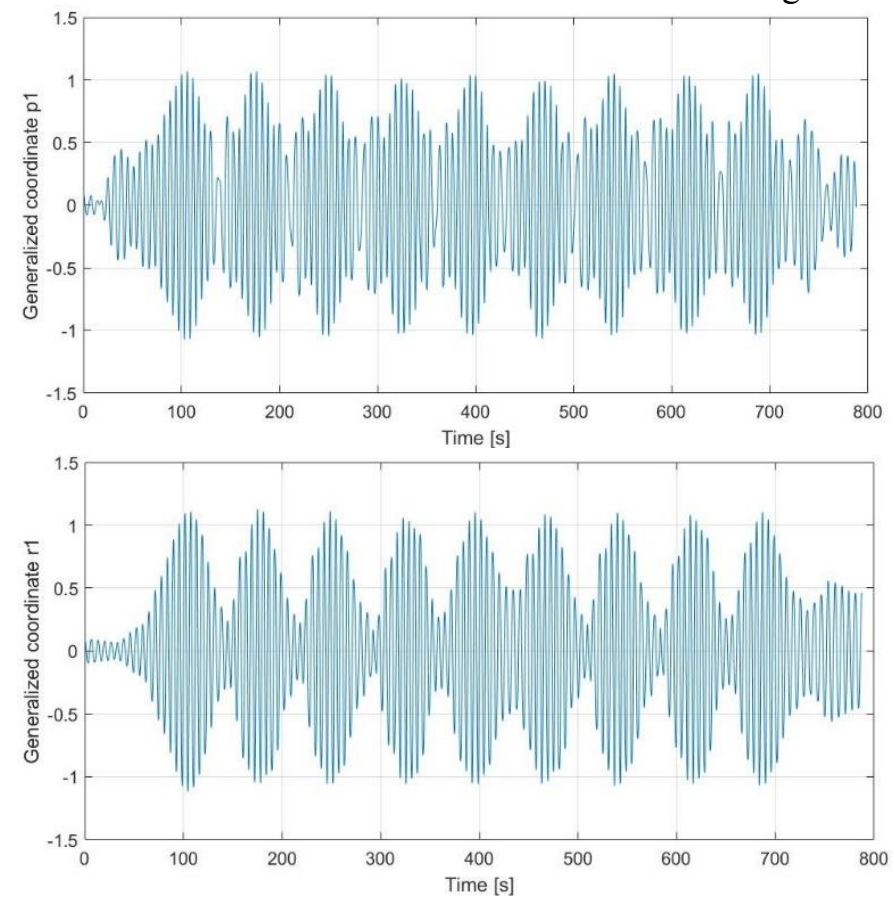

FIGURE 16 GENERALIZED COORDINATES FOR VALIDATING THE SWIRLING WAVE EFFECTS.
In the next step, the sway and roll motions are not restrained to simulate the actual cage responses in regular waves when the cage motion is coupled with interior swirling waves. The resulting cage motions are shown in Fig. 17.


FIGURE 17 COMPARISON OF THE SURGE MOTION OF THE CAGE IN REGULAR WAVES DEFINED IN TABLE 2. UPPER: SWIRLING WAVE IN THE TANK; LOWER: PLANAR WAVE IN THE TANK.

By comparing the magnitude of surge motion in Fig. 17, the cage motion with swirling wave happening inside the cage is obviously much more violent than the cage with the planar wave. As indicated by the comparison of Fig. 14 and Fig. 15 for a surging cylindrical tank with interior planar and swirling waves respectively, the sloshing-induced forces induced by swirling waves are much higher than the planar wave, which has caused the extra displacements of the cage in both surge and sway directions.

\section{Conclusion}

In this paper, a numerical model for studying the closed fish cage behavior under interior sloshing effect and exterior wave effect was presented. After some derivation and verification, the model is available to simulate the cage motions coupled with liquid sloshing effects inside the cage. Special attention was drawn to the swirling wave effect which can only be measured by a proper nonlinear sloshing solver. Although the wave frequency for exciting the swirling wave has to be close to the natural frequency, it may still occur in the reality. Comparison between the planar wave and swirling wave effects, showed that the hydrodynamic loads induced by 
swirling waves are much higher than planar waves, which will lead to violent cage motions even in the direction that is perpendicular to the incident wave direction. In addition, the violent cage motion and the free surface elevation oscillation may also influence the health and safety of fish. Future research should address the cages responses in irregular waves with coupled effects of nonlinear sloshing.

\section{REFERENCES}

[1] Faltinsen, O., and Timokha, A. N., 2009. Sloshing. Cambridge University Press.

[2] Cummins, W., 1962. The impulse response function and ship motions. Tech. rep., David Taylor Model Basin Washington DC.

[3] Equipment, A. Concept of closed fish cage. http://aquafarm.no/.Accessed June 15, 2018.

[4] Ibrahim, R. A., 2005. Liquid sloshing dynamics: theory and applications. Cambridge University Press.

[5] WU, G., X., MA, Q., W., TAYLOR, and R., E., 1998. "Numerical simulation of sloshing waves in a $3 \mathrm{~d}$ tank based on a finite element method". Applied Ocean Research, 20(6), pp. 337-355.

[6] Rognebakke, O. F., and Faltinsen, O. M., 2003. "Coupling of sloshing and ship motions". Journal of Ship Research, 47(3), pp. 208-221.

[7] Kim, Y., Nam, B. W., Kim, D. W., and Kim, Y. S., 2007. "Study on coupling effects of ship motion and sloshing". Ocean Engineering, 34(16), pp. 2176-2187.

[8] Strand, I. M., Srensen, A. J., Lader, P., and Volent, Z., 2013. "Modelling of drag forces on a closed flexible fish cage". Ifac Proceedings Volumes, 46(33), pp. 340-345.

[9] Strand, I. M., Srensen, A. J., Volent, Z., and Lader, P., 2016. "Experimental study of current forces and deformations on a half ellipsoidal closed flexible fish cage". Journal of Fluids Structures, 65, pp. 108-120.

[10] Kristiansen, D., Lader, P., Endresen, P. C., and Aksnes, V., 2018. "Numerical and experimental study on the seakeeping behavior of floating closed rigid fish cages". In ASME 2018 37th International Conference on Ocean, Offshore and Arctic Engineering, American Society of Mechanical Engineers, pp. V006T05A001-V006T05A001.

[11] Chernova, M. O., and Lukovsky, I. A., 2013. "Nonlinear modal equations for a levitating drop". Journal of Mathematical Sciences, 191(3), pp. 431-448. 